Article

\title{
Gender Differences in Factors Affecting Life Satisfaction of the Elderly with Multimorbidity in Korea
}

\author{
Jeonghyun Kim ${ }^{1} \mathbb{D}$, Minkyung Lee ${ }^{2}$ and Hyunju Dan ${ }^{1, * \mathbb{C}}$ \\ 1 College of Nursing, Ewha Womans University, Seoul 03760, Korea; jeonghyunkim@ewha.ac.kr \\ 2 Infectious Disease Department, Weill Cornell Medicine, New York, NY 10065, USA; mkmk8888@naver.com \\ * Correspondence: hidan@hanmail.net
}

check for

updates

Citation: Kim, J.; Lee, M.; Dan, H. Gender Differences in Factors Affecting Life Satisfaction of the Elderly with Multimorbidity in Korea. Nurs. Rep. 2021, 11, 54-63. https:// doi.org/10.3390/nursrep11010006

Academic Editor: Richard Gray

Received: 28 December 2020

Accepted: 28 January 2021

Published: 1 February 2021

Publisher's Note: MDPI stays neutral with regard to jurisdictional claims in published maps and institutional affiliations.

Copyright: (c) 2021 by the authors. Licensee MDPI, Basel, Switzerland. This article is an open access article distributed under the terms and conditions of the Creative Commons Attribution (CC BY) license (https:// creativecommons.org/licenses/by/ $4.0 /)$.

\begin{abstract}
To enhance the life satisfaction of the elderly with multimorbidity, it is necessary to investigate the relevant factors and to examine the differences in factors according to gender. The aim of this study was to identify factors affecting life satisfaction of the elderly with multimorbidity in the community by gender in Korea. We analyzed data from 2140 participants with multimorbidity who were aged 65 or older and participated in the Korean Longitudinal Study of Ageing (KLoSA) in 2016. A multivariate linear regression analysis was conducted to examine the factors affecting life satisfaction among male and female older participants with multimorbidity. The most common pattern of multimorbidity of women was hypertension and arthritis/rheumatism, while that of men was hypertension and diabetes mellitus. Some factors, such as depression, exercise, and number of chronic diseases, affected both male and female participants, but others related to life satisfaction varied by gender. Therefore, it is necessary to consider the characteristics of multiple chronic diseases, and policy support should be provided in consideration of gender differences to improve the life satisfaction of the elderly.
\end{abstract}

Keywords: multimorbidity; life satisfaction; gender; elderly; Korea

\section{Introduction}

Multimorbidity, in which a person has two or more chronic diseases simultaneously, has been a concern in the healthcare community, as the elderly population has increased. Multimorbidity prevalence in those aged 65 or older has been reported from $67.5 \%$ to $87 \%$ worldwide [1-3], and multimorbidity tends to increase with age [4]. In Korea, which entered the aging society in 2017, the population aged 65 or older increased to $14.9 \%$ of the total population in 2019 [5,6]. Along with the increase in the elderly population, the multimorbidity prevalence was found to be $37.9 \%-73.0 \%$, which is higher than the prevalence of single chronic diseases of $16.5 \%-29.2 \%$ [2,7], thus management of multimorbidity is necessary.

The patterns of multimorbidity vary depending on research participants and design $[7,8]$, and it has been reported that women are more susceptible to multimorbidity $[9,10]$. A systematic review study identified that the most common multimorbidity pattern was osteoarthritis with cardiovascular and/or metabolic diseases, but there were differences in patterns according to gender [11].

Compared to people with one chronic disease, the elderly with multimorbidity have increased risk of polypharmacy use [12], functional decline [13], greater health service use and health cost, poor quality of life [3], and increased mortality [14]. Chronic diseases affect one's attitude toward life, so Pan et al. [15] reported that the number of chronic diseases in the elderly aged 60 or older had a negative effect on life satisfaction. However, it is not well known how elderly people with multimorbidity subjectively evaluate their lives.

Life satisfaction is defined as the overall subjective evaluation of one's own life [16]. It is important to support the elderly to maintain a high level of life satisfaction, as the 
elderly with high life satisfaction tend to be more emotionally positive, maintain good health, and have a lower risk of mortality $[17,18]$. There are various factors that affect life satisfaction in the elderly. Sociodemographic factors include education, marital status, income, employment, health insurance, and participation in religious activities [19-21]. Health-related factors such as physical activity, cognition, and depression are also important factors [22-24].

In particular, even in people with the same disease, subjective evaluation of one's health or satisfaction with one's health can vary, and there might be different health outcomes. A qualitative study that explored the elderly's perception of their own health found that subjective components involving psychological and social factors had a greater effect on the health evaluation of the participants than did merely their objective health status [25]. Therefore, it is necessary to identify and manage factors affecting the satisfaction with life and health of the elderly who have multiple chronic diseases, but relevant studies are limited.

Because of differences in social norms as well as biological characteristics, different health outcomes may occur depending on gender [26], and life satisfaction may vary. The results of previous studies related to life satisfaction of the elderly have been inconsistent depending on gender. Some studies showed that the level of life satisfaction of older women was higher than that of older men $[27,28]$, while others reported no gender difference in life satisfaction [29].

The results of studies on factors influencing life satisfaction according to gender have not been consistent. Choi and Kim [27] found that monthly income affected life satisfaction of elderly women only, while other researchers [30] reported that income affected the life satisfaction of both genders. A large-scale, multi-country study of people aged 15-99 showed that unemployment and education level affected life satisfaction of both men and women, but affected men more than women [31]. In addition, religion and marital status also affected the life satisfaction of men and women differently [30,31]. Therefore, life satisfaction and affecting factors of the elderly with multimorbidity also are expected to vary by gender. The purpose of this study was to identify the multimorbidity patterns and factors affecting life satisfaction of the elderly with multimorbidity in the community by gender in Korea.

\section{Methods}

\subsection{Aim and Design}

This is a secondary analysis study aimed to identify the determinants of multimorbid older adult life satisfaction by gender using Korean Longitudinal Study of Ageing (KLoSA) data from 2016.

\subsection{Description of the Data Source, Procedure for Data Collection, and Sampling}

The KLoSA is a data-based panel that creates and implements effective social and economic policies to address the emerging trends as the population of Korea ages. This nationally representative survey has been conducted biennially with 10,254 Koreans aged 45 or older, excluding people dwelling in facilities and residents of Jeju Island, from 2006 to 2016 [32]. The survey contains seven domains (population, family, health, employment, income, assets, subjective expectancy, life satisfaction) and addresses the physical and psycho-social factors affecting older peoples' health status.

The KLoSA data were downloaded from the website of the Korean Employment Survey (https:/ / survey.keis.or.kr). The sixth phase of the KLoSA, which is the most recent data set available for public use, was used to assess the most current trends. Among the 10,254 participants, there were 6618 respondents in the sixth phase, of whom 4522 were older than 65 years. Among the latter, 2140 respondents who had more than two chronic diseases (hypertension, diabetic mellitus, malignant tumor, chronic lung disease, hepatic disease, heart disease, cerebrovascular disease, psychological disease, arthritis, rheumatism) were included in the final analysis. This study was approved by the institutional review 
board of the researchers' university (No. 162-13). This is a secondary analysis study aimed to identify the determinants of multimorbid older adult life satisfaction by gender using Korean Longitudinal Study of Ageing (KLoSA) data from 2016.

\subsection{Study Variables and Measurements}

The dependent variable in this study was life satisfaction, and the independent variables were categorized by sociodemographic, health behavioral, and health status factors.

\subsubsection{Sociodemographic Factors}

Sociodemographic factors included sex (male vs. female); age (years); education level (less than middle school vs. middle school or higher); marital status (married vs. not married; widowed and others); religion (yes vs. no); current employment (yes vs. no); interactions with close friends (more than once a week vs. less than once a week); and private health insurance (yes vs. no).

\subsubsection{Health Behavioral Factors}

Health behavioral factors were cigarette smoking (never smoked vs. smoker) and alcohol drinking (never drunk vs. drinker); regular exercise was assessed based on yes or no to the question, "Do you exercise more than once a week regularly?"

\subsubsection{Health Status Factors}

Health status factors comprised number of chronic diseases, cognition, depression, and grip strength. Self-reported diagnoses (hypertension, diabetic mellitus, malignant tumor, chronic lung disease, hepatic disease, heart disease, cerebrovascular disease, psychological disease, and arthritis/rheumatism) were counted as chronic diseases. Cognition was measured using the Mini-Mental State Examination (MMSE) in which the total score is 30 points, with higher scores indicating higher cognition (Korea Employment Information Service, 2018). Depression was measured using the Center for Epidemiological StudiesDepression Scale short-form 10 item (CES-D10). Each item was assessed as $0=$ no or 1 = yes, and the score was the sum of the 10 items; a higher score indicated a higher level of depressive symptoms. Grip strength was the mean of two values in kilograms measured for both hands using a grip strength dynamometer. In the previous study, reporting ageand gender- specific distributions of grip strength using data from the Korea National Health and Nutrition Examination Survey, the cut-off values for grip strength in healthy male and female older adults were 28.6 and $16.4 \mathrm{~kg}$, respectively [33].

\subsubsection{Life Satisfaction}

Life satisfaction was assessed using the question "How satisfied are you with your life compared to that of your peers in the same age group?" in terms of health and overall quality of life (QOL). Participants answered on a scale from 0 to 100 points at intervals of 10 points, with a higher score indicating greater satisfaction. Among the factors of life satisfaction, health and overall QOL were used as dependent variables in this study.

\subsection{Statistical Analyses}

IBM SPSS Statistics 25.0 (IBM, Inc., Armonk, NY, USA) was used for data analysis. Descriptive statistics of frequency, percentage, mean, and standard deviation were used to describe the variables. Differences between older males and females with multimorbidity were analyzed using Chi-square $(\chi 2)$ and independent t-tests. A multivariate linear regression analysis was conducted to understand the predictors of life satisfaction among older males and females with multimorbidity. Forward selection was used to determine the significant predictors that would be included in the multivariate model. All analysis was conducted by applying population weights calculated to reflect changes in the general distribution of the total population [34]. 


\section{Results}

\subsection{Differences between Older Males and Females with Multimorbidity}

Table 1 shows the differences in sociodemographics, health behavior, health status, and life satisfaction between older males and females with multimorbidity. Among the 2140 participants, 756 were male with a mean age of $74.17 \pm 6.51 ; 1384$ were female with a mean age of $76.22 \pm 7.22$. The men's education level was higher than that the women's; most of the women had been educated to elementary school or less $(75.6 \%)$, whereas $34.7 \%$ of the men had been educated to elementary school or less and $65.3 \%$ graduated middle school or higher. Most of the men were married $(86.4 \%)$, while $46.7 \%$ of the women were married. Half of the female participants (51.0\%) declared religious belief, in comparison to $36.4 \%$ of the males. The male participants who were currently employed numbered $30.6 \%$, while only $13.0 \%$ of the female participants were employed. Two-thirds of the women $(67.7 \%)$ met with close friends more than once a week, compared with $54.8 \%$ of males. More men (19.9\%) than women (14.2\%) had private health insurance.

Table 1. Differences of variables by gender $(n=2140)$.

\begin{tabular}{|c|c|c|c|c|}
\hline \multirow{2}{*}{\multicolumn{2}{|c|}{ Variables }} & Female $(n=1384)$ & $\begin{array}{c}\text { Male } \\
(n=756)\end{array}$ & \multirow[t]{2}{*}{$p$} \\
\hline & & \multicolumn{2}{|c|}{ Weighted \%, Mean (SD) } & \\
\hline \multicolumn{2}{|c|}{ Age (year) } & $76.22(7.22)$ & $74.17(6.51)$ & $<0.001$ \\
\hline \multirow{2}{*}{ Education } & $\begin{array}{c}\text { Elementary school or } \\
\text { less }\end{array}$ & 75.6 & 34.7 & \multirow{2}{*}{$<0.001$} \\
\hline & Middle school or higher & 24.4 & 65.3 & \\
\hline \multirow{2}{*}{ Marital status } & \multirow{2}{*}{$\begin{array}{c}\text { Married } \\
\text { Not married } \\
\text { (widowed, etc.) }\end{array}$} & 46.7 & 86.4 & \multirow{2}{*}{$<0.001$} \\
\hline & & 53.3 & 13.6 & \\
\hline \multirow{2}{*}{ Religion } & Yes & 51.0 & 36.4 & \multirow{2}{*}{$<0.001$} \\
\hline & No & 49.0 & 63.6 & \\
\hline \multirow{2}{*}{$\begin{array}{c}\text { Current } \\
\text { employment }\end{array}$} & Yes & 13.0 & 30.6 & \multirow[b]{2}{*}{$<0.001$} \\
\hline & No & 87.0 & 69.4 & \\
\hline \multirow{2}{*}{$\begin{array}{l}\text { Meeting with close } \\
\text { friends }\end{array}$} & More than once a week & 67.7 & 54.8 & \multirow[b]{2}{*}{$<0.001$} \\
\hline & Less than once a week & 32.3 & 45.2 & \\
\hline \multirow{2}{*}{ Private health insurance } & Yes & 14.2 & 19.9 & \multirow[b]{2}{*}{$<0.001$} \\
\hline & No & 85.8 & 80.1 & \\
\hline \multirow{2}{*}{ Cigarette smoking } & Never smoked & 94.0 & 31.1 & \multirow{2}{*}{$<0.001$} \\
\hline & smoker & 6.0 & 68.9 & \\
\hline \multirow{2}{*}{ Alcohol drinking } & Never consumed & 74.7 & 18.8 & \multirow[b]{2}{*}{$<0.001$} \\
\hline & Has consumed & 25.3 & 81.2 & \\
\hline \multirow{2}{*}{ Regular exercise } & Yes & 25.9 & 40.6 & \multirow{2}{*}{$<0.001$} \\
\hline & No & 74.1 & 59.4 & \\
\hline \multicolumn{2}{|c|}{ Number of chronic diseases } & $2.68(0.87)$ & $2.52(0.75)$ & $<0.001$ \\
\hline \multicolumn{2}{|c|}{ Cognition } & $22.31(6.20)$ & $24.98(5.19)$ & $<0.001$ \\
\hline \multicolumn{2}{|c|}{ Depression } & $3.84(2.82)$ & $3.25(2.93)$ & $<0.001$ \\
\hline \multicolumn{2}{|c|}{ Grip strength } & $19.29(5.26)$ & $28.24(7.55)$ & $<0.001$ \\
\hline \multirow{2}{*}{ Satisfaction of life } & Health & $47.99(20.49)$ & $51.02(20.17)$ & $<0.001$ \\
\hline & Overall quality of life & $56.22(17.33)$ & $59.18(17.21)$ & $<0.001$ \\
\hline
\end{tabular}

In terms of health behavioral factors, most male participants were smokers and drinkers $(68.9 \%$ and $81.2 \%$, respectively), while most of the female participants had never smoked or drunk alcohol (94.0\% and $74.7 \%$, respectively). However, more men (40.6\%) exercised regularly than did women $(25.9 \%)$.

Health status factors were number of chronic diseases, cognition, depression, and grip strength. The overall health status of females was lower than that of males; females had a larger number of chronic diseases (2.68 \pm 0.87 and $2.52 \pm 0.75$, respectively); mean MMSE score was $24.98 \pm 5.19$ in males and $22.31 \pm 6.20$ in females; females had more depressive 
symptoms than males ( $3.84 \pm 2.82$ and $3.25 \pm 2.93)$; and the mean grip strength of males was higher than that of females (19.29 \pm 5.26 and $28.24 \pm 7.55)$.

Male participants were more satisfied with their health and lives than were female participants, with mean health QOL scores of $51.02 \pm 20.17$ and $47.99 \pm 20.49$, respectively, and mean overall QOL of $59.18 \pm 17.21$ and $56.22 \pm 17.33$.

\subsection{Differences in Multimorbidity by Gender}

Differences in self-reported diagnosed chronic diseases between older males and females are shown in Figure 1. Hypertension was the most common chronic disease in both females and males (84.7\% and $83.3 \%$, respectively). However, arthritis/rheumatism (which was the second-most frequent disease for females) was much more common in females than males ( $71.2 \%$ and $30.8 \%$, respectively). A chronic disease that affected women more than men was psychological disease $(12.3 \%$ and $9.4 \%)$.

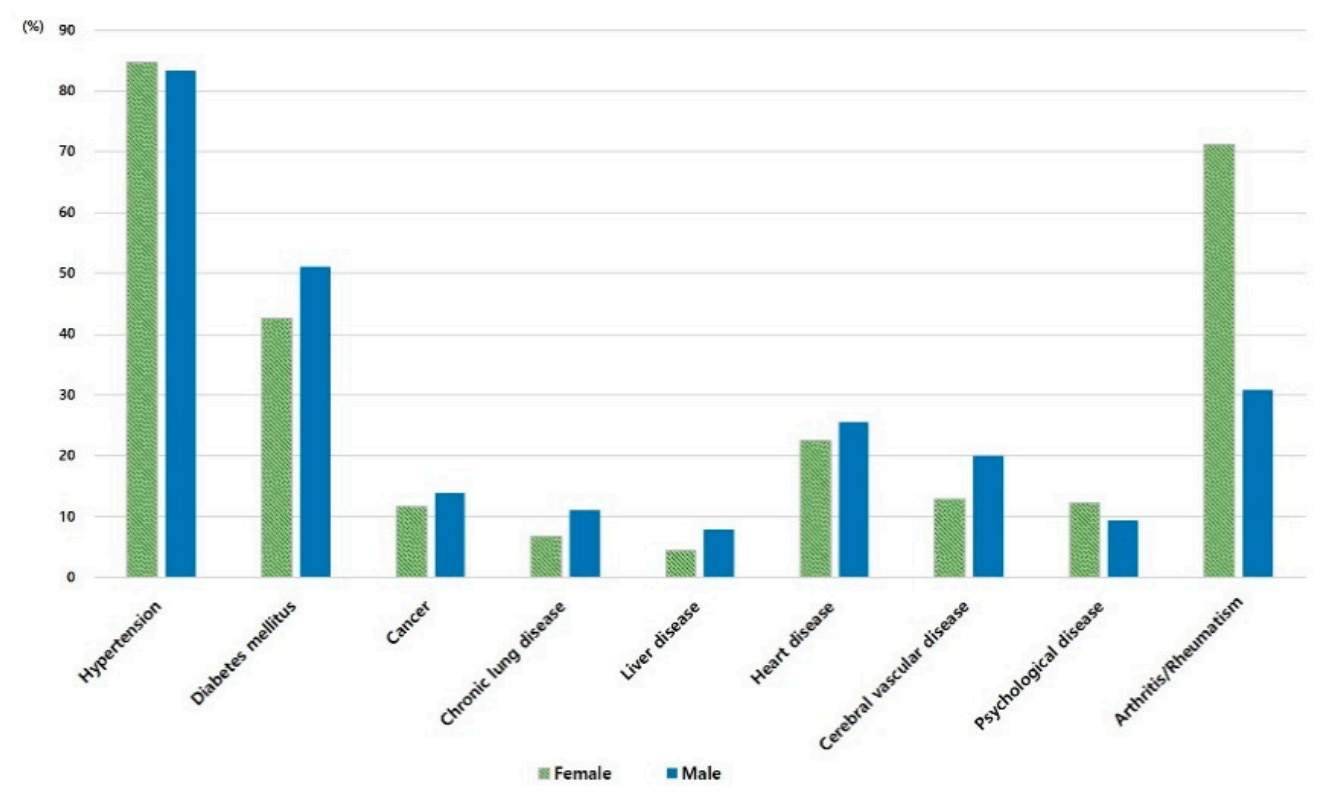

Figure 1. Self-reported diagnosed chronic diseases by gender.

Table 2 describes the data of the included 882 females (63.7\%) and 438 males $(57.9 \%)$ to determine the 10 most common combinations of multimorbidity. The most common combination of females was hypertension and arthritis/rheumatism (24.0\%), while that of males was hypertension and diabetes mellitus (18.2\%). All 10 of the male combinations included hypertension, while six of 10 female combinations involved arthritis/rheumatism.

Table 2. The most frequent multimorbidity type by gender.

\begin{tabular}{ccccc}
\hline & Female & $\boldsymbol{n}(\mathbf{\%})$ & Male & $\boldsymbol{n}(\mathbf{\%})$ \\
\hline 1 & HTN, AR & $333(24.0)$ & HTN, DM & $138(18.2)$ \\
2 & HTN, DM, AR & $168(12.1)$ & HTN, AR & $68(8.9)$ \\
3 & HTN, DM & $118(8.5)$ & HTN, HD & $49(6.4)$ \\
4 & HTN, HD, AR & $59(4.2)$ & HTN, DM, HD & $40(5.2)$ \\
5 & DM, AR & $47(3.4)$ & HTN, DM, AR & $35(4.6)$ \\
6 & HTN, HD & $45(3.2)$ & HTN, CVD & $34(4.5)$ \\
7 & HTN, DM, HD, AR & $36(2.6)$ & HTN, Cancer & $26(3.4)$ \\
8 & HTN, DM, HD & $27(1.9)$ & HTN, DM, CVD & $19(2.5)$ \\
9 & HTN, CVD & $25(1.8)$ & HTN, CLD & $16(2.1)$ \\
10 & HTN, CVD, AR & $24(1.7)$ & HTN, DM, Cancer & $13(1.7)$
\end{tabular}

Note. HTN = hypertension; AR = arthritis / rheumatism; DM = diabetes mellitus; HD = heart disease; CVD = cerebral vascular disease; $\mathrm{CLD}=$ chronic lung disease. 


\subsection{Predictors of Life Satisfaction in Older Females and Males with Multimorbidity}

Table 3 shows the factors influencing satisfaction with health among older people with multimorbidity according to gender. Among female participants, depression, cognition, exercise, number of chronic diseases, current employment, religion, and education were significantly related to satisfaction with health. Among male participants, depression, cognition, exercise, number of chronic diseases, current employment, grip strength, and smoking were significantly associated with satisfaction with health.

Table 3. Factors affecting life satisfaction with health by gender $(n=2140)$.

\begin{tabular}{|c|c|c|c|c|c|c|c|c|}
\hline \multirow{2}{*}{ Variables } & \multicolumn{4}{|c|}{ Female $(n=1384)$} & \multicolumn{4}{|c|}{ Male $(n=756)$} \\
\hline & B & S.E. & $\beta$ & $p$ & B & S.E. & $\beta$ & $p$ \\
\hline Depression & -2.286 & 0.182 & -0.316 & $<0.001$ & -1.967 & 0.236 & -0.286 & $<0.001$ \\
\hline Cognition & 0.487 & 0.085 & 0.148 & $<0.001$ & 0.549 & 0.137 & 0.141 & $<0.001$ \\
\hline $\begin{array}{l}\text { Exercise } \\
\text { (ref. No) }\end{array}$ & 5.790 & 1.158 & 0.124 & $<0.001$ & 5.530 & 1.325 & 0.135 & $<0.001$ \\
\hline Number of chronic diseases & -2.868 & 0.557 & -0.122 & $<0.001$ & -3.565 & 0.839 & -0.133 & $<0.001$ \\
\hline $\begin{array}{c}\text { Current } \\
\text { employment (ref. No) }\end{array}$ & 3.859 & 1.465 & 0.063 & 0.009 & 3.373 & 1.463 & 0.077 & 0.021 \\
\hline $\begin{array}{l}\text { Religion } \\
\text { (ref. No) }\end{array}$ & 2.526 & 0.973 & 0.062 & 0.010 & & & & \\
\hline $\begin{array}{c}\text { Education } \\
\text { (ref. Elementary school or less) }\end{array}$ & 2.309 & 1.155 & 0.048 & 0.046 & & & & \\
\hline Grip strength & & & & & 0.309 & 0.094 & 0.116 & 0.001 \\
\hline \multirow[t]{2}{*}{$\begin{array}{l}\text { Smoking } \\
\text { (ref. No) }\end{array}$} & & & & & -2.998 & 1.346 & -0.069 & 0.026 \\
\hline & \multicolumn{4}{|c|}{ Adjusted $\mathrm{R}^{2}=0.249, \mathrm{~F}=66.650(p<0.001)$} & \multicolumn{4}{|c|}{ Adjusted $\mathrm{R}^{2}=0.290, \mathrm{~F}=45.026(p<0.001)$} \\
\hline
\end{tabular}

The factors influencing satisfaction with QOL among older people with multimorbidity are shown in Table 4. Depression, exercise, number of chronic diseases, religion, cognition, and smoking were the significant factors among females; those of males were depression, exercise, number of chronic diseases, marriage, and private health insurance.

Table 4. Factors affecting life satisfaction with overall quality of life by gender $(n=2140)$.

\begin{tabular}{|c|c|c|c|c|c|c|c|c|}
\hline \multirow{2}{*}{ Variables } & \multicolumn{4}{|c|}{ Female $(n=1384)$} & \multicolumn{4}{|c|}{ Male $(n=756)$} \\
\hline & B & S.E. & $\beta$ & $p$ & B & S.E. & $\beta$ & $p$ \\
\hline Depression & -2.587 & 0.151 & -0.422 & $<0.001$ & -2.349 & 0.189 & -0.400 & $<0.001$ \\
\hline Exercise (ref. No) & 4.052 & 0.960 & 0.102 & $<0.001$ & 5.811 & 1.092 & 0.166 & $<0.001$ \\
\hline $\begin{array}{l}\text { Number of } \\
\text { chronic } \\
\text { diseases }\end{array}$ & -1.878 & 0.468 & -0.094 & $<0.001$ & -2.253 & 0.709 & -0.099 & 0.002 \\
\hline Religion (ref. No) & 2.108 & 0.814 & 0.061 & 0.010 & & & & \\
\hline Cognition & 0.165 & 0.069 & 0.059 & 0.017 & & & & \\
\hline Smoking (ref. No) & -3.888 & 1.689 & -0.053 & 0.021 & & & & \\
\hline Marriage (ref. No) & & & & & 6.678 & 1.563 & 0.133 & $<0.001$ \\
\hline \multirow[t]{2}{*}{ Private health insurance (ref. No) } & & & & & 4.594 & 1.333 & 0.107 & 0.001 \\
\hline & \multicolumn{4}{|c|}{ Adjusted $\mathrm{R}^{2}=0.261, \mathrm{~F}=82.618(p<0.001)$} & \multicolumn{4}{|c|}{ Adjusted $\mathrm{R}^{2}=0.294, \mathrm{~F}=63.784(p<0.001)$} \\
\hline
\end{tabular}

\section{Discussion}

This study analyzed the differences in multimorbidity pattern and life satisfaction according to gender using secondary data of the KLoSA. The combination of hypertension, diabetic mellitus, and arthritis was frequent in both males and females; the most frequent combination of multimorbidity in elderly females was hypertension and arthritis (22.4\%), and six of their top 10 combinations included arthritis. In contrast, hypertension and diabetes mellitus was the most frequent combination in elderly males (18.2\%); $8.9 \%$ of 
them had hypertension and arthritis, and arthritis was included in two of the top 10 combinations. According to a 2020 report by the World Health Organization, $18.0 \%$ of women and $9.6 \%$ of men older than 60 years had symptomatic arthritis; $80 \%$ of those with arthritis had limitations in movement; and $25 \%$ could not perform their major activities of daily living (ADLs) [35].

Arthritis tends to affect elderly females more than it does elderly males, and males performed more regular exercise than did females. Regular exercise is the most significant factor in satisfaction with health and overall QOL. Although pain caused by arthritis is known to interfere with regular exercise [36], proper exercise can relieve pain and improve physical function $[37,38]$. Therefore, elderly women need to be encouraged to exercise regularly.

In this study, the number of married male elderly was higher than the female elderly. In addition, this study found that elderly men were more satisfied with their health and overall QOL than were women, which is not consistent with the results of several previous studies that elderly women's life satisfaction level was higher or not significantly different from men's $[27,28]$. The average life expectancy of men and women in Korea in 2018 is 79.7 and 85.7 years, respectively, but the life expectancy excluding the disease period is 64.4 years in both males and females, showing that women live longer than men in unhealthy conditions and alone [39]. Therefore, it is necessary to study the change in life satisfaction among the elderly according to age group. In addition, socioeconomic factors such as economic status can affect health status, resulting in gender differences [26]. In a recent study [40], investigating gender differences in QOL among the elderly in lowand middle-income countries, elderly men reported better QOL than women, and income was one of the factors significantly related to QOL. Although South Korea's annual GDP per capita reached USD $\$ 30,000$ in 2018, making it a high-income country [41], it has the largest difference in income poverty rates between people aged over $65(43.8 \%)$ and the total population (17.4\%) among OECD countries; also, the elderly poverty rate was $49.0 \%$ in women and $37.1 \%$ in men [42].

Income level was not included in this study, but employment rate and use of private insurance were lower in women than men, indicating worse financial status among women. Since elderly financial status is associated with not only physical and mental health, but also QOL [40,43], gender-specific efforts are required to alleviate poverty in the elderly.

In this study, the factors affecting satisfaction with health and overall QOL in the elderly were different according to gender. Depression, cognition, regular exercise, number of chronic diseases, and employment status were significant factors in satisfaction with health in both elderly women and men, and depression, regular exercise, and number of chronic diseases were significant factors in satisfaction with overall QOL. Multimorbidity most significantly affects satisfaction with health and QOL of both elderly men and women, and these findings were consistent with previous studies [7,44]. However, most healthcare services in Korea are designed to treat single diseases [45]. Therefore, in primary care, management and support for the elderly with multimorbidity need to be provided and improved.

The study analyzed cognition, depression, and grip strength as well as the number of co-morbid diseases as elderly health status factors. These factors influence each other and affect elder life satisfaction. The elderly female participants in this study had more chronic diseases, lower cognition level, and more depression symptoms than the males. These factors significantly affect life satisfaction, which was somewhat consistent with previous studies. Previous studies reported that elderly women's cognitive function level was lower than that of men's [46,47] and cognitive capacity was the most influential factor in life satisfaction among both elderly women and men $[23,48]$. Depression is another important factor that affects elder life satisfaction. Onishi et al. [49] found that depression was a significant determinant of life satisfaction among elderly women, while cognition and comorbidity were not. Similarly, Puvill et al. [50] found that depressive symptoms and loneliness were strongly associated with life satisfaction. Besides, elder grip strength is 
a major factor that predicts patient nutritional status, physical function, and mortality in previous studies [51] and it is known that grip strength and depression or cognitive capacity have an inverse correlation [52,53]. Therefore, we need to comprehensively approach the physical and psychological factors that influence elder life satisfaction.

In this study, it is difficult to confirm any causal relationships because the crosssectional design could not confirm the temporal arrangement between variables and all factors that may affect the relationship between variables could not be controlled. The number and type of diseases reported in the study was limited and the severity of multimorbidity was not considered, which may affect life satisfaction in the elderly, so we could not confirm their impacts on life satisfaction. In addition, since this study used secondary data to analyze factors affecting life satisfaction, there were limitations in including the selection of variable measurement tools and other factors that could also affect life satisfaction, such as economic level, family relationship, living arrangement, area of residence, and nutritional status. Therefore, follow-up studies that reflect these factors are suggested. Nevertheless, one of the strengths of this study is that the patterns of multimorbidity and the factors influencing life satisfaction among the elderly are identified by gender using a nationwide sample representing the elderly in Korea.

\section{Conclusions}

This study analyzed the life satisfaction of 2140 elderly men and women with multimorbidity using KLoSa data from 2016. Hypertension and arthritis was the most common combination in women, and hypertension and diabetes mellitus was the most common in men. The factors influencing life satisfaction of both male and female elderly were depression, regular exercise, and number of chronic diseases. Factors affecting the elderly satisfaction with life varied by gender. This study could provide a basis for policy makers to consider gender differences and the characteristics of multimorbidities to improve elder life satisfaction. In addition, since this study focused on the individual factors that affect life satisfaction with health and QOL of the elderly, further research on social factors and systems that affect the health and life satisfaction of the elderly is needed, and should be accessed using the Dahlgren-Whitehead model [54] or Bronfenbrenner's ecological system [55].

Author Contributions: Conceptualization, J.K., M.L. and H.D.; methodology, J.K., M.L. and H.D.; formal analysis, J.K., M.L. and H.D.; writing-original draft preparation, J.K., M.L. and H.D.; writingreview and editing, J.K., M.L. and H.D.; visualization, J.K. and M.L.; project administration, H.D.; funding acquisition, J.K., M.L. and H.D. All authors have read and agreed to the published version of the manuscript.

Funding: This research received no external funding.

Institutional Review Board Statement: The study was conducted according to the guidelines of the Declaration of Helsinki, and approved by the Institutional Review Board of Ewha Womans University (No.162-13 and 20 June 2018).

Informed Consent Statement: Patient consent was waived due to a secondary analysis.

Data Availability Statement: Publicly available datasets were analyzed in this study. This data can be found here: http://survey.keis.or.kr/klosa/klosadownload/List.jsp.

Conflicts of Interest: The authors declare no conflict of interest.

\section{References}

1. Abad-Díez, J.M.; Calderón-Larrañaga, A.; Poncel-Falcó, A.; Poblador-Plou, B.; Calderón-Meza, J.; Sicras-Mainar, A.; ClerenciaSierra, M.; Prados-Torres, A. Age and gender differences in the prevalence and patterns of multimorbidity in the older population. BMC Geriatr. 2014, 14, 75. [CrossRef]

2. Ministry of Health and Welfare \& Korea Institute for Health and Social Affairs. 2017 Report on Elderly Survey. Sejong. Available online: http: / / www.mohw.go.kr/react/jb/sjb030301vw.jsp?PAR_MENU_ID=03\&MENU_ID=032901\&page=1\&CONT_SEQ= 344953 (accessed on 28 November 2020). 
3. Quah, J.H.M.; Wang, P.; Ng, R.R.G.; Luo, N.; Tan, N.C. Health-related quality of life of older Asian patients with multimorbidity in primary care in a developed nation. Geriatr. Gerontol. Int. 2017, 17, 1429-1437. [CrossRef]

4. Ward, B.W.; Black, L.I. State and regional prevalence of diagnosed multiple chronic conditions among adults aged $\geq 18$ yearsUnited States, 2014. MMWR Morb. Mortal Wkly Rep. 2016, 65, 735-738. [CrossRef]

5. Statistics Korea. 2017. Population and Housing Census. Available online: https://www.korea.kr/news/pressReleaseView.do? newsId=156290510 (accessed on 18 January 2021).

6. Statistics Korea. 2019 Population Status and Prospects of the World and Korea. Available online: http:/ / kostat.go.kr/portal/ korea/kor_nw/1/1/index.board?bmode=read\&aSeq=377226 (accessed on 18 January 2021).

7. Park, B.; Ock, M.; Lee, H.A.; Lee, S.; Han, H.; Jo, M.-W.; Park, H. Multimorbidity and health-related quality of life in Koreans aged 50 or older using KNHANES 2013-2014. Health Qual. Life Outcomes 2018, 16, 186. [CrossRef] [PubMed]

8. Agur, K.; McLean, G.; Hunt, K.; Guthie, B.; Mercer, S.W. How does sex influence multimorbidity? Secondary analysis of a large nationally representative dataset. Int. J. Environ. Res. Public Health 2016, 13, 391. [CrossRef]

9. King, D.E.; Xiang, J.; Pillkerton, C.S. Multimorbidity trends in United States adults, 1988-2014. J. Am. Board Fam. Med. 2018, 31, 503-513. [CrossRef] [PubMed]

10. Yao, S.-S.; Cao, G.-Y.; Han, L.; Chen, Z.-S.; Huang, Z.-T.; Gong, P.; Hu, Y.; Xu, B. Prevalence and patterns of multimorbidity in a nationally representative sample of older Chinese: Results from the China Health and Retirement Longitudinal Study. J. Gerontol. A Biol. Sci. Med. Sci. 2020, 75, 1974-1980. [CrossRef]

11. Violan, C.; Foguet-Boreu, Q.; Flores-Mateo, G.; Salisbury, C.; Blom, J.; Freitag, M.; Glynn, L.; Muth, C.; Valderas, J.M. Prevalence, determinants and patterns of multimorbidity in primary care: A systematic review of observational studies. PLoS ONE 2014, 9 , e102149. [CrossRef] [PubMed]

12. Rieckert, A.; Trampisch, U.S.; Klaaßen-Mielke, R.; Drewelow, E.; Esmail, A.; Johansson, T.; Keller, S.; Kunnamo, I.; Löffler, C.; Mäkinen, J.; et al. Polypharmacy in older patients with chronic diseases: A cross-sectional analysis of factors associated with excessive polypharmacy. BMC Fam. Pract. 2018, 19, 113. [CrossRef]

13. Gu, J.; Chao, J.; Chen, W.; Xu, H.; Zhang, R.; He, T.; Deng, L. Multimorbidity and health-related quality of life among the community-dwelling elderly: A longitudinal study. Arch. Gerontol Geriatr. 2018, 74, 133-140. [CrossRef]

14. Nunes, B.P.; Flores, T.R.; Mielke, G.I.; Thumé, E.; Facchini, L.A. Multimorbidity and mortality in older adults: A systematic review and meta-analysis. Arch. Gerontol. Geriatr. 2016, 67, 130-138. [CrossRef] [PubMed]

15. Pan, Y.; Chan, S.H.W.; Xu, Y.; Yeung, K.C. Determinants of life satisfaction and self-perception of ageing among elderly people in China: An exploratory study in comparison between physical and social functioning. Arch. Gerontol Geriatr. 2019, 84, 103910. [CrossRef] [PubMed]

16. Organisation for Economic Co-operation and Development. "Life satisfaction". In Society at a Glance 2019: OECD Social Indicators; OECD Publishing: Paris, French, 2019. [CrossRef]

17. Bai, X.; Yang, S.; Knapp, M. Sources and directions of social support and life satisfaction among solitary Chinese older adults in Hong Kong: The mediating role of sense of loneliness. Clin. Interv. Aging 2018, 13, 63-71. [CrossRef] [PubMed]

18. Kimm, H.; Sull, J.W.; Gombojav, B.; Yi, S.-W.; Ohrr, H. Life satisfaction and mortality in elderly people: The Kangwha Cohort Study. BMC Public Health 2012, 12, 54. [CrossRef] [PubMed]

19. Kang, D.-H. Effect of religion on the satisfaction of the elderly's life. J. KoCon. A. 2020, 20, 212-221. [CrossRef]

20. Kolosnitsyna, M.; Khorkina, N.; Dorzhiev, H. Determinants of life satisfaction in older Russians. Ageing Intl. 2017, 42, 354-373. [CrossRef]

21. Tran, N.L.T.; Wassmer, R.W.; Lascher, E.L. The Health Insurance and Life Satisfaction Connection. J Happiness Stud. 2017, 18, 409-426. [CrossRef]

22. Adams, T.R.; Rabin, L.A.; Da Silva, V.G.; Katz, M.J.; Fogel, J.; Lipton, R.B. Social support buffers the impact of depressive symptoms on life satisfaction in old age. Clin Gerontol. 2016, 39, 139-157. [CrossRef]

23. Banjare, P.; Dwivedi, R.; Pradhan, J. Factors associated with the life satisfaction amongst the rural elderly in Odisha, India. Health Qual. Life Outcomes 2015, 13, 201. [CrossRef]

24. Parra-Rizo, M.A.; Sanchis-Soler, G. Satisfaction with life, subjective well-being and functional skills in active older adults based on their level of physical activity practice. Int. J. Environ. Res. Public Health 2020, 17, 1299. [CrossRef]

25. Tkatch, R.; Musich, S.; MacLeod, S.; Kraemer, S.; Hawkins, K.; Wicker, E.R.; Armstrong, D.G. A qualitative study to examine older adults' perceptions of health: Keys to aging successfully. Geriatr. Nurs. 2017, 38, 485-490. [CrossRef] [PubMed]

26. Manandhar, M.; Hawkes, S.; Buse, K.; Nosrati, E.; Magar, V. Gender, health and the 2030 agenda for sustainable development. Bull World Health Organ. 2018, 96, 644-653. [CrossRef] [PubMed]

27. Choi, H.-K.; Kim, J.-E. Gender difference of community-residing elderly's satisfaction with life and influential factors. J. KoCon. A. 2018, 18, 467-480. [CrossRef]

28. Resnick, B.; Boltz, M.; Galik, E.; Holmes, S.; Fix, S.; Zhu, S. Gender differences in function, physical activity, falls medication use, and life satisfaction among residents in assisted living settings. Res. Gerontol. Nurs. 2020, 13, 31-39. [CrossRef]

29. Meggiolaro, S.; Ongaro, F. Life satisfaction among older people in Italy in a gender approach. Ageing Soc. 2015, 35, 1481-1504. [CrossRef]

30. Lee, S.-H.; Lee, J.; Choi, I. Life satisfaction in later life: The interplay of marital condition and income among elderly Koreans. Sustainability 2020, 12, 3483. [CrossRef] 
31. Joshanloo, M. Gender differences in the predictors of life satisfaction across 150 nations. Pers. Individ. Dif. 2018, 135, 312-315. [CrossRef]

32. Lim, Y.M.; Lee, S.R.; Choi, E.J.; Jeong, K.; Chung, H.W. Urinary incontinence is strongly associated with depression in middle-aged and older Korean women: Data from the Korean longitudinal study of ageing. Eur. J. Obstet. Gynecol. Reprod. Biol. 2018, 220, 69-73. [CrossRef]

33. Yoo, J.I.; Choi, H.; Ha, Y.C. Mean hand grip strength and cut-off value for sarcopenia in Korean adults using KNHANES VI. J. Korean Med. Sci. 2017, 32, 868-872. [CrossRef]

34. Korea Employment Information Service. 2018 User's Guide of Korean Longitudinal Study of Ageing. Available online: https:/ / survey.keis.or.kr/klosa/klosaguide/List.jsp (accessed on 15 October 2020).

35. World Health Organization. Chronic Diseases and Health Promotion. Available online: https://www.who.int/chp/topics/ rheumatic/en/ (accessed on 3 December 2020).

36. Dieppe, P.A.; Lohmander, L.S. Pathogenesis and management of pain in osteoarthritis. Lancet 2005, 365, 965-973. [CrossRef]

37. Hurley, B.F.; Hanson, E.D.; Sheaff, A.K. Strength training as a countermeasure to aging muscle and chronic disease. Sports Med. 2011, 41, 289-306. [CrossRef] [PubMed]

38. Kim, G.J.; Oh, H.; Lee, S.; Lee, K.; Kim, K. Effects of resistance exercise using the elastic band on the pain and function of patients with degenerative knee arthritis. J. Phys. Ther. Sci. 2020, 32, 52-54. [CrossRef] [PubMed]

39. Statistics Korea. Life Expectancy and Life Expectancy excluding Disease Period. Available online: https://www.index.go.kr/ potal/info/idxKoreaView.do?idx_cd=2758 (accessed on 19 January 2021).

40. Lee, K.H.; Xu, H.; Wu, B. Gender differences in quality of life among community-dwelling older adults in low-and middle-income countries: Results from the Study on global AGEing and adult health (SAGE). BMC Public Health 2020, 20, 114. [CrossRef] [PubMed]

41. Choi, H.G. The status of South Korea's economy: A middle-income or a high-income country? East Asia Found. 2019, 126, 1-6.

42. Organisation for Economic Co-operation and Development. "Old-age income poverty". In Pensions at a Glance 2019: OECD and G20iIndicators; OECD Publishing: Paris, French, 2019. [CrossRef]

43. Kang, E.N. Current state and challenges of senior employment programs. Health Welfare Forum 2017, $251,28-39$.

44. Marques, A.; Peralta, M.; Gouveia, É.R.; Chávez, F.G.; Aleiro, M.G. Physical activity buffers the negative relationship between multimorbidity, self-rated health and life satisfaction. J. Public Health 2018, 40, e328-e335. [CrossRef]

45. Boehmer, K.R.; Abu Dabrh, A.M.; Gionfriddo, M.R.; Erwin, P.; Montori, V.M. Does the chronic care model meet the emerging needs of people living with multimorbidity? A systematic review and thematic synthesis. PLoS ONE 2018, 13, e0190852. [CrossRef]

46. Lei, X.; Hu, Y.; McArdle, J.J.; Smith, J.P.; Zhao, Y. Gender differences in cognition among older adults in China. J. Hum. Resour. 2012, 47, 951-971. [CrossRef]

47. Ahrenfeldt, L.J.; Scheel-Hincke, L.L.; Kjærgaard, S.; Möller, S.; Christensen, K.; Lindahl-Jacobsen, R. Gender differences in cognitive function and grip strength: A cross-national comparison of four European regions. Eur. J. Public Health 2019, 29, 667-674. [CrossRef]

48. Peitsch, L.; Tyas, S.L.; Menec, V.H.; St John, P.D. General life satisfaction predicts dementia in community living older adults: A prospective cohort study. Int. Psychogeriatr. 2016, 28, 1101-1109. [CrossRef]

49. Onishi, C.; Yuasa, K.; Sei, M.; Ewis, A.A.; Nakano, T.; Munakata, H.; Nakahori, Y. Determinants of life satisfaction among Japanese elderly women attending health care and welfare service facilities. J. Med. Investig. 2010, 57, 69-80. [CrossRef] [PubMed]

50. Puvill, T.; Lindenberg, J.; de Craen, A.J.; Slaets, J.P.; Westendorp, R.G. Impact of physical and mental health on life satisfaction in old age: A population based observational study. BMC Geriatr. 2016, 16, 194. [CrossRef]

51. Bohannon, R.W. Muscle strength: Clinical and prognostic value of hand-grip dynamometry. Curr. Opin. Clin. Nutr. Metab. Care 2015, 18, 465-470. [CrossRef] [PubMed]

52. McDowell, C.P.; Gordon, B.R.; Herring, M.P. Sex-related differences in the association between grip strength and depression: Results from the Irish Longitudinal Study on Ageing. Exp. Gerontol. 2018, 104, 147-152. [CrossRef] [PubMed]

53. Sternäng, O.; Reynolds, C.A.; Finkel, D.; Ernsth-Bravell, M.; Pedersen, N.L.; Dahl Aslan, A.K. Grip Strength and Cognitive Abilities: Associations in Old Age. J. Gerontol. B Psychol. Sci. Soc. Sci. 2016, 71, 841-848. [CrossRef]

54. Dahlgren, G.; Whitehead, M. Policies and Strategies to Promote Social Equity in Health; Institute for Futures Studies: Stockholm, Sweden, 1991.

55. Bronfenbrenner, U. Ecological systems theory. In Six Theories of Child Development: Revised Formulations and Current Issues; Vasta, R., Ed.; Jessica Kingsley Publishers: London, UK, 1992; pp. 187-249. 